\title{
Calcitonin treatment for intersternocostoclavicular ossification: clinical experience in two cases
}

\author{
Takashi Misaki, Shigeharu Dokoh, Eigo Mori
}

\begin{abstract}
Intersternocostoclavicular ossification is a benign arthro-osteitis of the upper anterior chest of unknown cause. Two patients with acute exacerbation of this disorder were successfully treated with intramuscular injections of an eel calcitonin analogue (40 units three times a week). Besides symptomatic relief of local pain and swelling, serial scintigrams showed quantitative improvement in radiophosphonate uptake. The rapid alleviation of pain implies that the hormone has a central analgesic effect, in addition to its direct influence on bone cells and antiinflammatory action. In one patient the disease was associated with palmoplantar pustulosis, which was cured with oral colchicine, whereas the other patient did not have such skin lesions. Despite a hypothetical link between palmoplantar pustulosis and intersternocostoclavicular ossification, colchicine had no beneficial impact on the bone pain. Salmon calcitonin delivered by nasal spray was tried for the second patient but failed, probably because of insufficient drug delivery.
\end{abstract}

The initial favourable results described here warrant future use of calcitonin injection on a larger number of patients with intersternocostoclavicular ossification.

Intersternocostoclavicular ossification ${ }^{12}$ is a benign orthopaedic disorder of the upper anterior chest wall. Known also as sternocostoclavicular hyperostosis, ${ }^{3}$ it is characterised by inflammatory ossification of the joints and hyperostosis of the surrounding bones. Judging from the common association of this ossification with palmoplantar pustulosis, ${ }^{45}$ the 'focal infection' mechanism postulated in palmoplantar pustulosis $^{67}$ might also play a part in the pathogenesis of this joint disease. Antibiotics, however, are usually ineffective on the joint symptoms-namely, focal pain, swelling, and restriction of motion. ${ }^{2}$ The pathophysiology of intersternocostoclavicular ossification is still to be clarified, and no specific treatment has yet been established for this disorder. Usually, nonsteroidal anti-inflammatory agents are prescribed, but these provide little relief for severely affected patients. We report two patients in the exacerbation phase of typical intersternocostoclavicular ossification who were successfully treated with intramuscular injections of a calcitonin analogue. The preparation used was a synthetic eel calcitonin with a slight chemical modification, which made it more stable than the natural form, while retaining its potent bioactivity. $^{8}$

\section{Case reports}

CASE 1

The patient, a 45 year old man, had a history of severe head injury sustained in a traffic accident about 20 years previously, from which he recovered. For five years he had had mild but persistent pain in his shoulders and the back of his neck, which increased in December 1986 causing sleep loss and restricted motion. When he visited our clinic the skin on the upper anterior chest was reddish with localised heat. There was also slight swelling and severe percussion pain in the region. During the previous year he had noticed pustules on his palms, which had caused neither pain nor itching, and similar lesions on the soles of his feet were found on physical examination. The radiograph and radiophosphonate scintiscan (figs 1 and 2) were characteristic of intersternocostoclavicular ossification, ${ }^{2910}$ and he was admitted to hospital. Laboratory data suggested chronic active inflammation together with mild liver dysfunction. Isoenzyme analysis of alkaline phosphatase showed increases of both skeletal and hepatic components. A bone biopsy specimen taken at the medial portion of the left clavicle showed non-suppurative chronic inflammation of bone marrow with prominent periosteal hyperostosis, thus confirming the diagnosis histopathologically. ${ }^{2}$ At the same time the results of a microscopic study of the skin biopsy specimen were compatible with palmoplantar pustulosis.

After two days' treatment with a synthetic eel calcitonin analogue (Elcatonin) in a dose of $\mathbf{4 0}$ units intramuscularly three times a week the localised bone pain and soft tissue swelling rapidly subsided and serum alkaline phosphatase levels were lowered (table 1). The severity of pain was estimated by the frequency of doses of analgesic drugs needed to alleviate it. Additionally, a quantitative assessment of the therapeutic response was made by serial bone scans as described for Paget's disease, ${ }^{11}$ with some modifications. Briefly, two fixed regions of interest were set, one in an affected bone (in this case the left clavicle) and the other in the mandible as an internal reference (fig 2), and the ratio of uptake per pixel in these two regions was calculated. From a previous basic evaluation of the reproducibility a change in this uptake ratio of more than $20 \%$ was deemed significant. In this patient more than $50 \%$ reduction was seen after the first month of treatment with calcitonin 


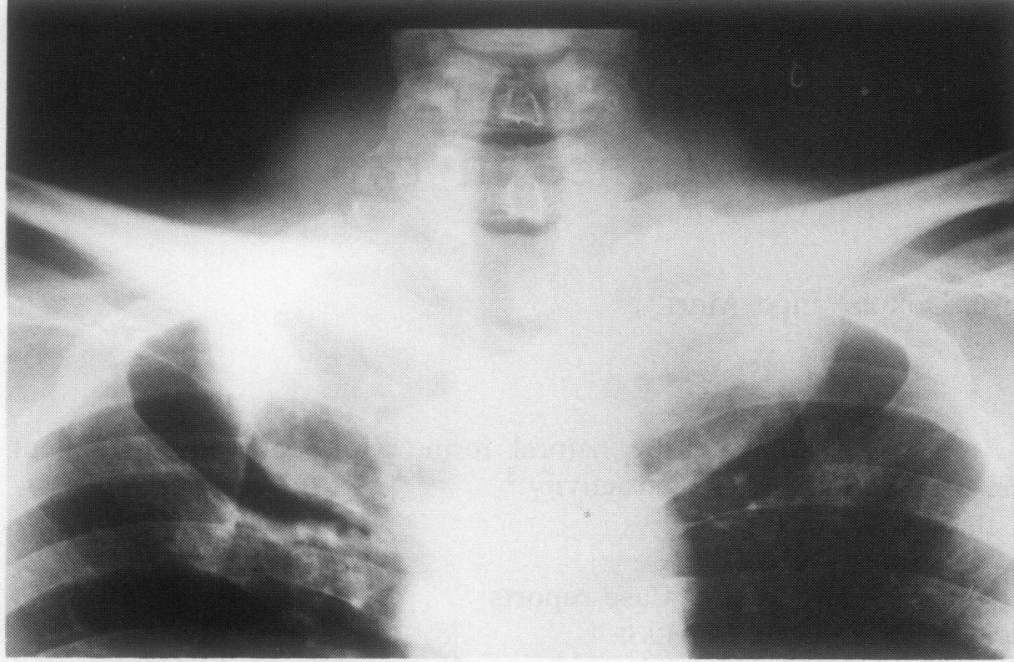

Figure 1 Bone $x$ ray film of the upper chest in patient 1. Prominent, symmetrical hyperostosis and swelling were evident in bilateral first ribs and medial halves of the clavicles.

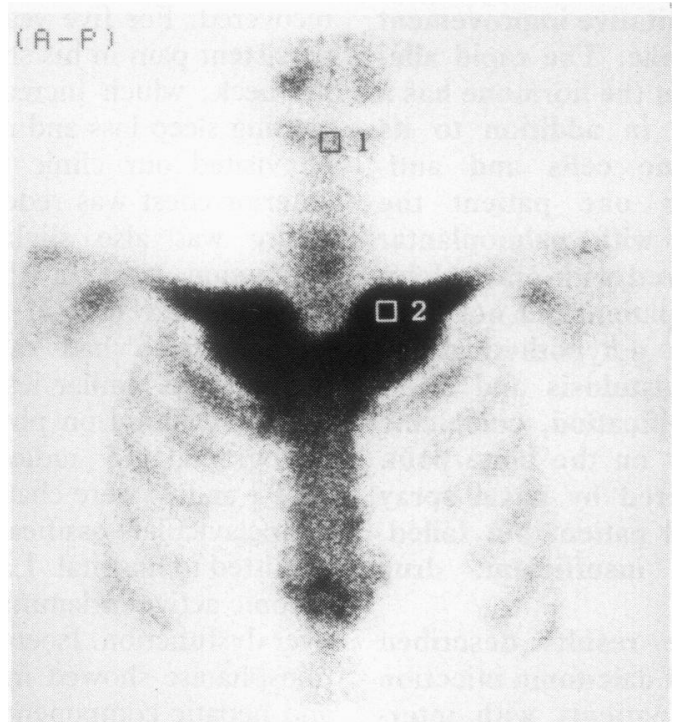

Figure 2 Chest spot image of bone scintigram in patient 1. Intense uptake of technetium-99m hydroxymethylenediphosphonate was noted at the hyperostotic regions seen in the radiogram. Radioactivity in the right second rib and the whole sternum was also mildly increased. The numbered squares indicate regions of interest for the quantitative assessment of abnormal uptake. In this scintigram the ratio of count/pixel of a diseased bone (region 2) to that of a normal reference area (region 1 ) was $7 \cdot 6$. analogue, though the abnormal uptake was still visually prominent in scintigraphic images. Despite these improvements, values and titres of serological markers remained high, with a relapse of palmoplantar pustulosis, which had previously been effectively treated with a corticosteroid ointment after the histological diagnosis. Injection of the calcitonin analogue was stopped after the ninth week, and oral colchicine was started at $0.5 \mathrm{mg}$ twice daily, which normalised these indices and improved the skin pustules. Unfortunately, the occurrence of abdominal pain after four weeks' treatment with colchicine necessitated reduction of the dose to $0.5 \mathrm{mg}$ daily, which caused increased abnormalities in laboratory data but not the dermatological lesions. Colchicine was discontinued after another 12 months, and this was associated with gradual improvement in serological values. During and after the colchicine regimen joint symptoms were well controlled with nonsteroidal anti-inflammatory drugs, except for occasional episodes of minor left clavicular pain.

\section{CASE 2}

A 67 year old housewife was referred to our clinic for detailed examination of her right clavicle, in which she had had pain for 20 years. Three years previously she had undergone surgical curettage of the clavicle under the diagnosis of 'osteomyelitis', and thereafter had been treated continuously with several oral antibiotics, which had little effect. She had a past history of tonsillitis in her childhood but lacked the skin lesions of palmoplantar pustulosis. Upon presentation venous dilatation was seen in the skin overlying the left clavicle, together with a percussion pain of the upper anterior chest wall. Unlike case 1 the laboratory data (table 2) were not remarkable, and serological tests for streptococcal antigens were negative. Radiological and scintigraphic findings were typical of intersternocostoclavicular ossification as in case 1 , and the diagnosis was confirmed histologically by a review of the specimen taken during a previous operation. Because of the encouraging results obtained in

Table 1 Treatment course of case 1

\begin{tabular}{|c|c|c|c|c|c|c|c|c|c|c|c|c|}
\hline & \multicolumn{8}{|l|}{1987} & \multicolumn{4}{|l|}{1988} \\
\hline & $23 \mathfrak{F a n}$ & $6 \mathrm{Feb}$ & $25 \mathrm{Feb}$ & 9 Mar & $23 \mathrm{Mar}$ & $30 \mathrm{Apr}$ & 20 May & $12 \mathrm{Sep}$ & $5 \mathcal{F a n}$ & $29 \mathrm{Mar}$ & 10 May & $12 \mathrm{ful}$ \\
\hline \multirow{2}{*}{\multicolumn{13}{|c|}{$\begin{array}{l}\text { Treatment } \\
\text { Calcitonin analogue } \\
\text { intramuscularly } 40 \mathrm{U}, 3 \text { times/week } \\
\text { Steroid ointment (for pustules) } \\
\text { Colchicine orally } \\
1.0 \mathrm{mg} / \text { day } \\
0.5 \mathrm{mg} / \text { day }\end{array}$}} \\
\hline & & & & & & & & & & & & \\
\hline $\begin{array}{l}\text { Laboratory data } \\
\text { AP* (IU/l) }^{*} \text { (I) } \\
\text { CRP*† }^{*} \\
\text { ESR }^{*}(\mathbf{m m} / \mathbf{h}) \\
\text { ASLO }^{*} \text { titre }\end{array}$ & $\begin{array}{l}303 \\
5+ \\
113 \\
640\end{array}$ & $\begin{array}{c}196 \\
4+ \\
110 \\
480\end{array}$ & $\begin{array}{c}176 \\
3+ \\
107 \\
320\end{array}$ & $\begin{array}{c}173 \\
2+ \\
93 \\
480\end{array}$ & $\begin{array}{c}158 \\
5+ \\
84 \\
480\end{array}$ & $\begin{array}{r}160 \\
\frac{43}{240}\end{array}$ & $\begin{array}{c}155 \\
2+ \\
76 \\
160\end{array}$ & $\begin{array}{c}177 \\
1+ \\
30 \\
120\end{array}$ & $\begin{array}{c}175 \\
2+ \\
72 \\
120\end{array}$ & $\frac{193}{22}$ & $\begin{array}{c}159 \\
6+ \\
115^{+} \\
80\end{array}$ & $\begin{array}{r}\frac{143}{46} \\
80\end{array}$ \\
\hline ASK* titre & 5120 & 5120 & 10240 & 10240 & 5120 & 2560 & 640 & 2560 & 5120 & ND & 640 & 640 \\
\hline Uptake ratio in bone scan & $7 \cdot 60$ & ND & $3 \cdot 14$ & ND & $3 \cdot 88$ & $2 \cdot 65$ & $5 \cdot 10$ & $4 \cdot 00$ & $4 \cdot 30$ & ND & ND & $3 \cdot 27$ \\
\hline $\begin{array}{l}\text { Pain } \\
\text { Skin pustles }\end{array}$ & $\begin{array}{r}+++ \\
++\end{array}$ & $\begin{array}{l}+ \\
+\end{array}$ & \pm & $\begin{array}{l}- \\
-\end{array}$ & - & \pm & - & - & \pm & - & \pm & - \\
\hline
\end{tabular}


Table 2 Treatment course of case 2

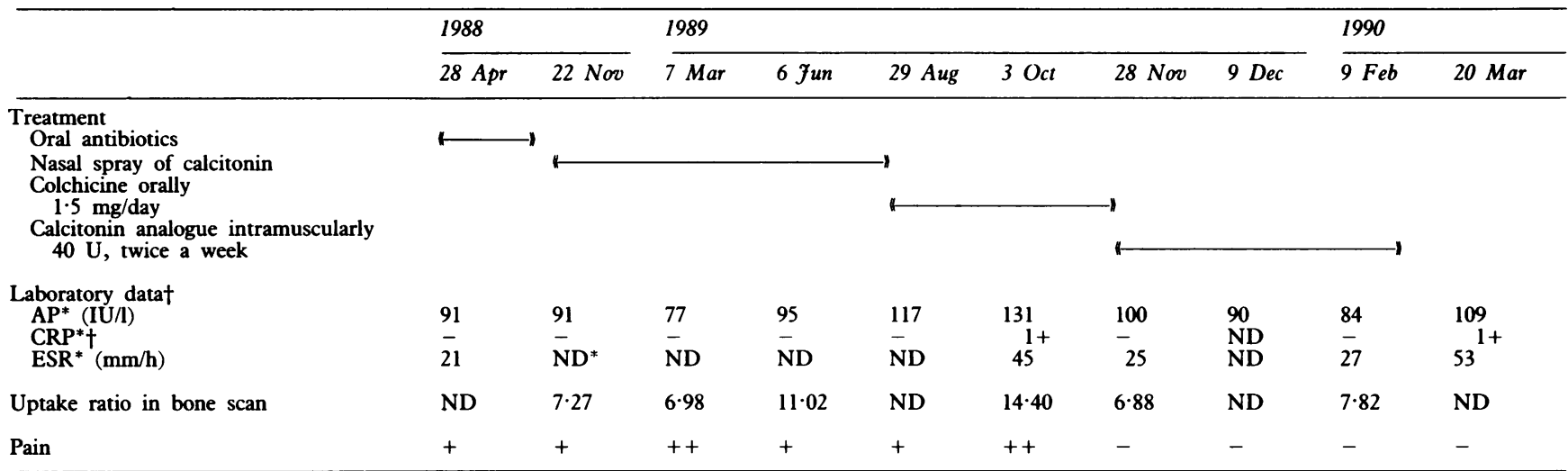

${ }^{*} \mathrm{AP}=$ alkaline phosphatase, normal 28-110 IU/1; $\mathrm{CRP}=\mathrm{C}$ reactive protein; $\mathrm{ESR}=$ erythrocyte sedimentation rate; $\mathrm{ND}=$ not done.

+ Antistreptolysin $O$ and antistreptokinase were negative throughout the course

fAntistreptolysin $O$ and antistreptokinase were negative throug
fCRP was measured by a precipitin test in capillary tubes.

case 1 calcitonin treatment was considered. In an attempt to obviate the pain of intramuscular injection a nasal spray of synthetic salmon calcitonin (SMC-20-051) was used in doses of 200 units daily for eight months, with virtually no significant analgesic effect. There was even a transient worsening of the bone pain with increase of serum alkaline phosphatase and $\mathrm{C}$ reactive protein. Oral colchicine $0.5 \mathrm{mg}$ three times daily was prescribed for the next three months, again with no significant relief. When intramuscular calcitonin analogue was started at 40 units twice a week an analgesic effect took place from day 4, with improvement of the uptake ratio on bone scan and normalisation of laboratory indices. The venous dilatation of local skin gradually disappeared. The pain recurred during a holiday period when the hospital was closed and injections were not available for two weeks, but disappeared promptly after resumption. In the eighth week of the regimen gastrointestinal symptoms of epigastralgia, decreased appetite, and soft stool emerged but were controlled with an $\mathrm{H} 2$ receptor blocking agent and other stomach drugs. After a total of 16 weeks the calcitonin analogue was discontinued with no relapse of joint symptoms. At the time of this report the patient remains well without drugs.

\section{Discussion}

To our knowledge this is the first report of the treatment of intersternocostoclavicular ossification with calcitonin. Although the pain in this disease usually waxes and wanes even without any treatment, incidental spontaneous remission could not explain the prompt improvement of symptoms seen in both patients after calcitonin injections, or the worsening again when calcitonin was unavailable early in the treatment course of case 2 .

This therapeutic trial was first conceived owing to the report of favourable effects of human calcitonin in Tietze's disease, ${ }^{12}$ a benign condition with costochondral pain and swelling. As in Tietze's disease, bone pain in intersternocostoclavicular ossification was alleviated early in the course of treatment. This supports the idea of a central analgesic effect of the peptide $^{1314}$ working together with its antiinflammatory effects. ${ }^{15}$ Moreover, the noted quantitative improvement in bone scintigraphy may reflect termination of joint calcification and hyperostosis. At first sight this may seem contradictory to the restoration by calcitonin of decreased bone mass in osteoporosis. ${ }^{1617}$ But the hormone might indirectly suppress new bone formation by osteoblasts through its well known inhibitory influence on osteoclasts, ${ }^{18} 19$ as the activity of those two types of cell is coupled. ${ }^{20}$

Having noted the close association between intersternocostoclavicular ossification and palmoplantar pustulosis, Sonozaki and colleagues proposed the term pustulotic arthroosteitis (PAO) ${ }^{4}$ suggesting a common cause for these two conditions. They analysed clinical features of accumulated cases and suggested that pustulotic arthro-osteitis was a seronegative spondyloarthritis. ${ }^{5}$ There are a significant minority of patients with intersternocostoclavicular ossification without palmoplantar pustulosis, however, as in case 2, whose symptoms and radiographic features are indistinguishable from those of patients with palmoplantar pustulosis. Interestingly, patient 2 did not have raised titres of antistreptolysin $\mathrm{O}$ and antistreptokinase, whereas patient 1 (with palmoplantar pustulosis) did, suggesting that other factors besides focal infection may play a part in the pathogenesis of intersternocostoclavicular ossification, at least in cases without palmoplantar pustulosis. In fact, the raised titres of these antistreptococcal antibodies in patient 1 might have simply reflected an anamnestic response to chronic inflammation, either in his liver, skin, or bone and joint. In any case our experience in these two cases showed that injection of calcitonin analogue produced symptomatic relief in the acutely exacerbated clinical situations regardless of the associated skin disease. Thus the hormone must have exerted its effects by mechanisms not directly related to the putative common causenamely, focal infection.

The failure of treatment by calcitonin nasal spray in case 2 might have been due to 
insufficient drug delivery. When the patient was examined in an otolaryngology clinic she was found to have chronic sinusitis, which might have led to reduced absorption of the hormone through nasal mucosa. Furthermore, if a spray were used in the future for patients without mucosal problems it would be necessary to determine the size of the nasal dose required to exert effects equivalent to those of the agent given intramuscularly.

Theoretically colchicine might have suppressed the inflammation of bones and joints, as in gout, ${ }^{21}$ but it was found not to reduce the pain of intersternocostoclavicular ossification. On the other hand, the drug has been used successfully for palmoplantar pustulosis, ${ }^{22}$ presumably owing to its inhibitory effects on leucocytes. In case 1 , it certainly cured the skin lesion and lowered the inflammatory indices and titres of antistreptococcal antibodies.

Long term calcitonin treatment can be hindered by a so called 'escape' phenomenon, 2324 though this was not found in our cases. As the severity of symptoms in intersternocostoclavicular ossification is known to fluctuate naturally, however, an escape could be avoided by using calcitonin injections only during the waxing phase. Clinically, this would mean trying to discontinue the hormone after several months of the regimen, just as was done in the two cases reported here. After a period without calcitonin the responsiveness of target organs should be restored, and if symptoms reoccur they could be quelled again with the same regimen.

To conclude, our initial encouraging results warrant further use of calcitonin injections in cases of acute aggravation of intersternocostoclavicular ossification. In due course accumulated clinical data from a larger number of patients should help to clarify both the pathogenesis of the disease and the mechanism of action of the drug.

1 Sonozaki H, Furusawa S, Seki H, Kurokawa T, Tateishi A, Kabata K. Four cases with symmetrical ossifications between the clavicles and the first ribs of both sides. Kanto fournal of Orthopedics and Traumatology 1974; 5: 244-7. (In Journal of

2 Sonozaki H, Azuma A, Okai K, et al. Clinical features of 22 cases with "inter-sterno-costo-clavicular ossification." Arch Orthop Trauma Surg 1979; 95: 13-22.
3 Köhler H, Uehlinger E, Kutzner J, West T B. Sternocostoclavicular hyperostosis: painful swelling of the sternum clavicles, and upper ribs. Ann Intern Med 1977; 87: 192-4

4 Sonozaki $H$, Kawashima $M$, Hongo $O$, et al Incidence of arthro-osteitis in patients with pustulosis palmaris plantaris. Ann Rheum Dis 1981; 40: 554-7.

5 Sonozaki $\mathrm{H}$, Mitsui $\mathrm{H}$, Miyanaga Y, et al. Clinical features of 53 cases with pustulotic arthro-osteitis. Ann Rheum Dis 1981 ; 40: $547-53$.

6 Yamanaka N, Sambe S, Kataura A. Conceptual understand ing of pustulosis palmaris et plantaris as an immune complex disease due to focal tonsillar infection
Otolaryngol Suppl (Stockh) 1983; 401: 31-5.

7 Kuki K, Tabata T. Immunological studies on tonsils with recurrent tonsillitis and focus-tonsil with pustulosis palmaris et plantaris. Acta Otolaryngol Suppl (Stockh) 1984; 416 $20-9$.

8 Morikawa T, Munekata E, Sakakibara T, Noda T, Otani M. Synthesis of eel-calcitonin and $\left[\mathrm{Asu}^{1},{ }^{7}\right]$-eel calcitonin contribution of the disulfide bond to the hormonal activity. Experientia 1976; 32: 1104-6.

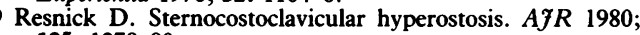
135: 1278-80.

10 Rosenthal L, Burke D L. A radionuclide and radiographic diagnosis of sternocostoclavicular hyperostosis. Clin Nucl diagnosis of sternocos 1986 ; 11 : $322-4$.

11 Dokoh S, Fukunaga M, Yamamoto I, Torizuka K, Morita R. Evaluation by using radionuclide uptake of bone in Paget's disease of bone: special reference to treatment with calcitonin. Radioisotopes 1988; 37: 339-42.

12 Ricevuti G. Effects of human calcitonin on pain in the treatment of Tietze's syndrome. Clin Ther 1985; 7: 669-73.

13 Pecile A, Ferri S, Braga P C, Olgiati V R. Effects of intracerebroventricular calcitonin in the conscious rabbit. Experientia 1975; 31: 332-3.

14 Yamamoto M, Kumagai F, Tachikawa S, Maeno H. Lack of effect of levallorphan on analgesia induced by intraventricular application of porcine calcitonin in mice. Eur $\mathcal{J}$ Pharmacol 1979; 55: 211-3.

15 Whitfield J F, MacManus J P, Franks D J, Braceland B M Gillan D J. Calcium-mediated effects of calcitonin on cyclic GMP formation and lymphoblast proliferation in thymocyte populations exposed to prostaglandin $\mathrm{E}_{1} . \mathcal{7}$ Cell cyte populations exposed
Physiol 1972; 80: 315-28

16 Cohen S H, Dombrowski C S, Hauser W, Klopper J, Atkin $H$ L. Effects of porcine calcitonin on calcium metabolism in osteoporosis. F Clin Endocrinol 1971; 33: 719-28.

17 Langer B, de Siebenthal J, Baud L, Baud C A, Mach R S Effets de l'administration prolongée de diverses calcitonines dans l'ostéoporose humaine: étude clinique, histologique et microradiographique. Ann Med Interne (Paris) 1971; 122: 149-55.

18 Feldman R S, Krieger N S, Tashiian A H Jr. Effects of parathyroid hormone and calcitonin on osteoclast formation in vitro. Endocrinology 1980; 107: 1137-43.

19 Rao L G. Heersche J N M, Marchuk L L, Sturtridge W. Immunohistochemical demonstration of calcitonin binding Immunohistochemical demonstration of calcitonin binding
to specific cell types in fixed rat bone tissue. Endocrinology
$1981 ; 108: 1972-8$.

20 Rasmussen H, Bordier P. Bone cells-morphology and physiology. In: The physiological and cellular basis of metabolic bone disease. Baltimore: Williams and Wilkins, 1974: 8-104.

21 Woodbury D M, Fingl E. Drugs employed in the therapy of gout. In: Goodman L S, Gilman A, eds. The pharmacologica basis of therapeutics. 5th ed. New York: Macmillan, 1975 $350-5$.

22 Takigawa $M$, Miyachi Y, Uehara $M$, Tagami H. Treatment of pustulosis palmaris et plantaris with oral dose of of pustulosis palmaris et plantaris with

23 Wright D R, Ivey J L, Tashijian A H Jr. Self-induced loss of calcitonin receptors in bone. A possible explanation for "escape" [abstract] Clin Res 1976; 24:461A.

24 Obie J F, Cooper C W. Loss of calcemic effects of calcitonin and parathyroid hormone infused continuously into rats using the Alzet osmotic minipump. $\mathcal{F}$ Pharmacol Exp The 1979; 209: 422-8. 